\title{
Analysis of the Behaviour of Semi Rigid Steel End Plate Connections
}

\author{
A. Bahaz ${ }^{1}$, S. Amara ${ }^{1}$, J.P. Jaspart ${ }^{2}$ and J.F. Demonceau ${ }^{2}$ \\ ${ }^{1}$ University Amar Telidji, SREML laboratory, Laghouat, Algeria \\ ${ }^{2}$ Liège University, ArGEnCo Department, Liège, Belgium
}

\begin{abstract}
The analysis of steel-framed building structures with full strength beam to column joints is quite standard nowadays. Buildings utilizing such framing systems are widely used in design practice. However, there is a growing recognition of significant benefits in designing joints as partial strength/semi-rigid. The design of joints within this partial strength/semi-rigid approach is becoming more and more popular. This requires the knowledge of the full nonlinear moment-rotation behaviour of the joint, which is also a design parameter. The rotational behaviour of steel semi rigid connections can be studied using the finite element method for the following three reasons: i) such models are inexpensive; ii) they allow the understanding of local effects, which are difficult to measure accurately physically, and iii) they can be used to generate extensive parametric studies. This paper presents a three-dimensional finite element model using ABAQUS software in order to identify the effect of different parameters on the behaviour of semi rigid steel beam to column end plate connections. Contact and sliding between different elements, bolt pretension and geometric and material non-linearity are included in this model. A parametric study is conducted using a model of two end-plate configurations: flush and extended end plates. The studied parameters were as follows: bolts type, end plate thickness and column web stiffener. Then, the model was calibrated and validated with experimental results taken from the literature and with the model proposed by Eurocode3. The procedure for determining the moment-rotation curve using finite element analysis is also given together with a brief explanation of how the design moment resistance and the initial rotational stiffness of the joint are obtained.
\end{abstract}

\section{Introduction}

Extended end-plate connections are widely used in steel structures as moment resistance connections and as an alternative to fully welded ones that have been considered for use in steel frames. These connections consist of end-plates welded to the end of beams and field bolted to the connecting columns as illustrated in Fig. 1. The understanding of the behaviour of joints is enhanced by developing analytical models. Various forms of analysis and mathematical modelling methods have been suggested in order to study the semi-rigid characteristics of beam-to-column joints and their influence on the response of the rest of structural members. Eurocode 3, Part 1.8 [1] includes a simplified analytical model to represent the semi-rigid connection behaviour based on the moment- rotation $(\mathrm{M}-\varphi)$ characteristics of the joint. The component method [1] is not applicable to end-plate joints with pre-tensioned bolts and research into these types of end-plate connections is therefore much needed [2].

Many researches on end-plate steel connections have been carried out analytically and experimentally in order to determine an accurate method for predicting the connection rotational behaviour. Pertold et al. [3] performed two experimental tests on beam-to-beam and beam-to-column joints. For both tests, failure occurred at the column flange in the compression zone. Lima et al. [4] tested three specimens to enable the prediction of the moment resistance and the rotation capacity about the minor axis of the beam-to-column semi-rigid joints. These investigations motivated the development of a mechanical model to assess the structural response of joints.

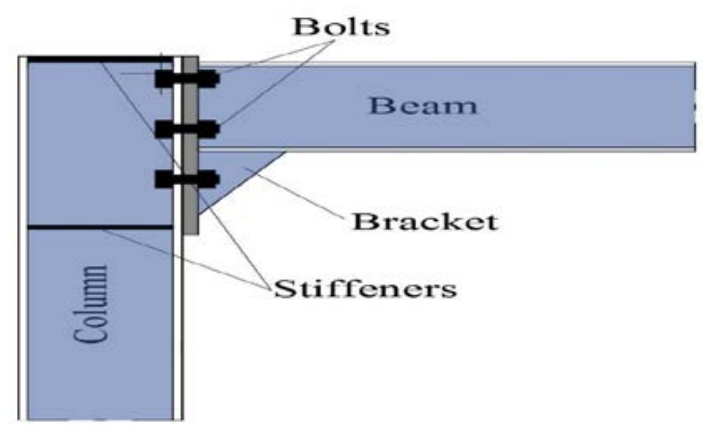

Fig. 1. Typical end-plate connection 
Furthermore, connection types and details are numerous and innovative with many parameters, that must be accounted collectively to characterise the behaviour of the joint. Such parameters include whether the end plate is flush or extended, whether the end plate extends beyond one or both of the beam flanges, the diameter and the grade of the bolts, the number of bolt rows, the vertical and horizontal spacing of the bolts, the end-plate thickness, the stiffening of steel and the coefficient of friction at the contact surface. Because of this, it is almost impossible to study the behaviour of these joints comprehensively except by physical tests [5].

However, due to limited number of tests, the numerical simulations are widely used currently. The more accurate finite element model for parametric analysis is particularly important [6]. The first study into joint behaviour using FEM has been carried out by Bose et al [7], which is related to welded beam-to-column joints, including: plasticity, strain hardening and buckling. Maggi et al. [8] performed parametric analyses on the behaviour of bolted extended end-plate connections using 3D models. Dai et al. [9] made a simulation study of ten (10) fire tests on restrained steel beam-column assemblies using five different types of joints: fin plate, flexible end- plate, flush end-plate, web cleat and extended end-plate.

The aim of this paper is to present a full $3 \mathrm{D}$ ABAQUS [16] FE model to obtain the behaviour of steel beam-to-column bolted extended and flush end-plate joints. This model includes: contact and sliding between different elements; bolt pre-tension; geometric and material non- linearity. The results from the FE Analysis (FEA) are verified by comparing the moment-rotation curve with those obtained from experimental results found in the literature and with the results achieved using the model proposed by EC3 [1]. A brief explanation of how the design of the moment resistance and the initial rotational stiffness of the joint are obtained.

\section{End-plate connections}

End-plate connections have become more popular in steel building constructions due to their economy, simplicity of fabrication, and good structural performance. In the literature end-plate connections have been presented with three typologies: header, flush and extended end-plate connections. From which five observations [9] can be made:

- The most studied are the extended and double end-plate connections.

- Most models use four bolts and no stiffeners.

- 3D FE are mostly used for bolts, although truss, beams and plane stress elements have been used. The nut is less commonly modelled, however, when it is modelled, a 3D FE are used.

The extended and the flush end-plate 6-bolts unstiffened connections was analysed in this work as shown in Fig. 2. The analysis was conducted using ABAQUS/Standard software [16]. Both materials and geometry nonlinearities were considered. All parts of the models are presented in detail as follows.

\section{Finite element modelling}

ABAQUS software[16] offers a wide range of options regarding element types, material behaviour and numerical solution controls, as well as graphic user interfaces (known as Abaqus/CAE), auto-meshers, and sophisticated postprocessors and graphics to speed the analyses. In this paper, the structural system modelling is based on the use of this software.

\subsection{Element types and meshing}

A suitable type of element needs to be selected for the finite element model to obtain reliable results [10]. The element C3D8I (an 8-node linear brick, incompatible mode) is adopted for H-shaped steel beams, columns, high strength bolts and plate.
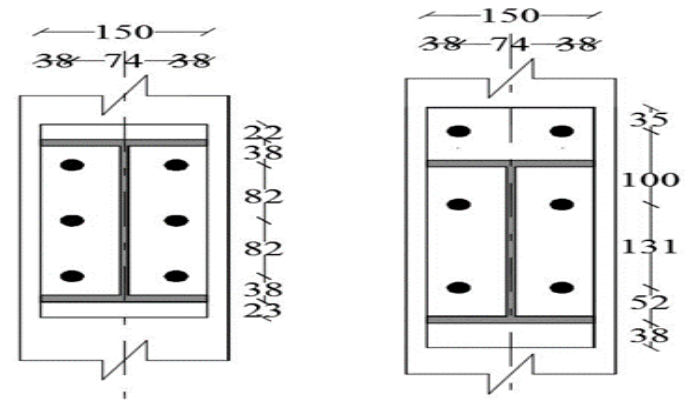

a) Detail dimensions of end plates.

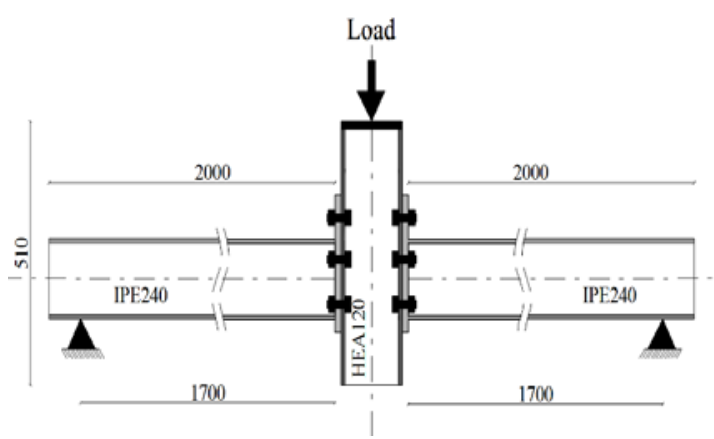

b) The specified dimensions.

Fig. 2. Model description.

This element can effectively avoid shear locking phenomenon (comparing with element C3D8R), which will significantly affect the initial stiffness of the connection [6]. Since this solid element has no rotational degree of freedom, the number of elements through the thickness of each component plate plays a critical role [10]. For the regions where the hexahedra formulation was not possible to be used the wedge approach was used with an element designated by C3D6 which is a 6-node linear triangular prism and constant pressure element [11].

To reduce the number of contact planes and the complexity of the model [12], the bolt nut forms an integral component with the bolt shank rather than as an individual part, as shown in Fig. 3.

Different mesh sizes have been examined to determine a reasonable mesh that provides both reliable results with 
less computational time. The results show that, if the mesh is too coarse, a convergence problem will occur as the contact element was used between the column flange and the endplate surface. However, if the mesh is too fine, the computational time will be excessive. The finite element mesh adopted for all joint components is shown in Fig.3, with the smallest and largest element sizes being $5 \mathrm{~mm}$ and $50 \mathrm{~mm}$, respectively. The fine mesh was created at the region around the bolts and studs to achieve reliable results. The finite element mesh of each specimen contains approximately 12300 elements.

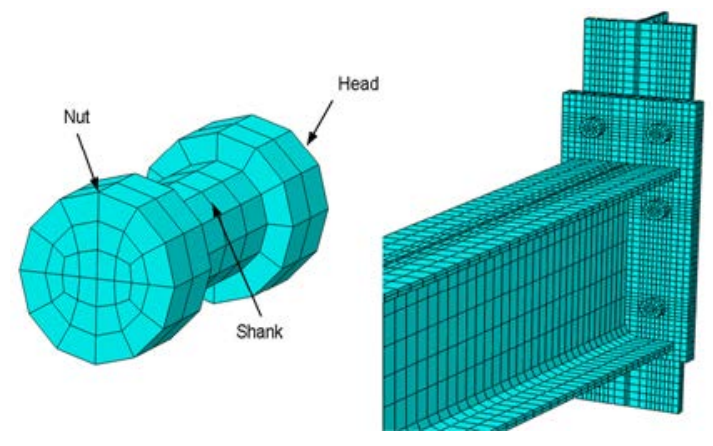

Fig. 3. Finite element model

\subsection{Material proprieties}

The material behaviour used for the joint was represented by the bilinear plus nonlinear stress-strain curve. The plasticity behaviour in the connection was represented by the isotropic work hardening assumption and the Von Mises criteria. The yield ultimate tensile strength and the elongation of the connection components are given in Table 1. These values were selected based on tensile coupon tests conducted on structural steel specimens [13].

Table 1. Mechanical properties.

\begin{tabular}{|l|c|c|c|}
\hline & $f_{y}(M P a)$ & $f_{u}(M P a)$ & $A \%$ \\
\hline Beam web & 343 & 456 & 27.0 \\
Beam flange & 356 & 480 & 33.5 \\
Column web & 345 & 456 & 27 \\
Column flange & 338 & 435 & 33.5 \\
End-plate & 310 & 464 & 27 \\
Bolts M16/8.8 & 893 & 110 & 5 \\
\hline
\end{tabular}

The true stress and true strain relationship is then obtained and tabulated for the use in ABAQUS [16] as shown in Fig. 4.

\subsection{Boundary conditions}

Due to the symmetry of geometry, one-half of a real specimen was modelled with double symmetry conditions. All nodes at the mid-span section of the column were prevented from translating in the $\mathrm{X}$ direction as shown in Fig. 5. For the application of the end support boundary conditions, the end of the steel beam was converted to a rigid body.

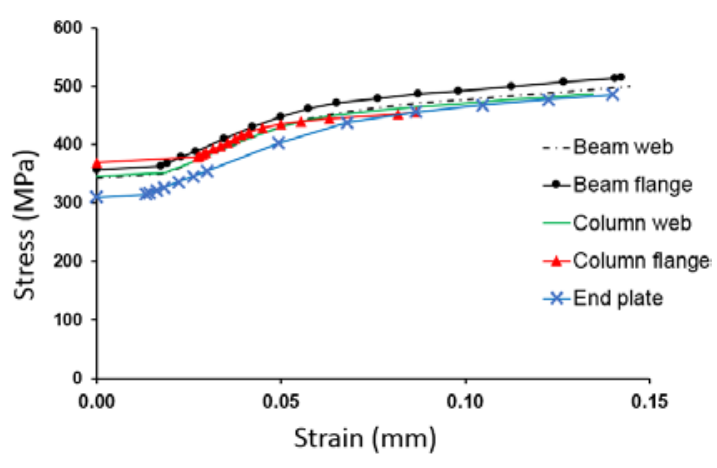

Fig. 4. True plastic stress-strain curves.

A reference point was specified on the rigid body and it was prevented from translation in the $\mathrm{X}$ direction to avoid the buckling effect. A support with only its translational displacements in the $\mathrm{Y}$ and $\mathrm{Z}$ directions restrained was defined herein to simulate a simply supported boundary condition.

\subsection{Contact interaction and constrain conditions}

The interaction between the different components of joint should be taken into consideration in the modelling. The contact between these components, viz. end platecolumn flange, bolt-column flange and bolt-end plate were represented using the surface-to-surface contact interaction technique.

One surface was taken as a master surface and the other as slave one. The normal behaviour is assumed to be a "hard" contact pressure-over closure relationship. Because of a tangential behaviour, penalty frictional formulation is used and according to Shi $G$ et al. numerical simulation results [5], the coefficient of friction was considered as 0.44 . The welds between the beam end plate and the column stiffeners were defined as a Tie constraint.

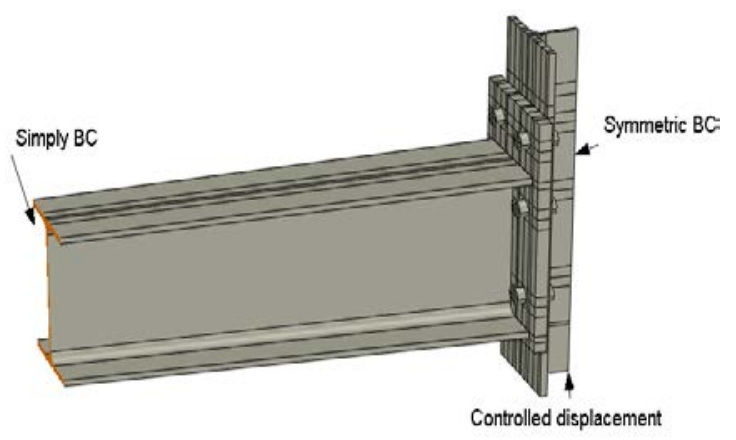

Fig. 5. Boundary conditions.

\subsection{Load application and analysis method}

A nonlinear analysis is carried out in two steps. In the first step the boundary conditions and contact are defined, loads are applied on the contact surfaces to make convergence easier, in the same step the pretension load was applied to bolts connecting the beam to the column.

The bolt load feature available in ABAQUS [16] was invoked in order to include the bolt pretension in this 
step and in the second step a displacement-controlled load was applied to the column using the arc length method (Riks) as the convergence algorithm.

This method is generally used to predict the unstable and nonlinear collapse of a structure. It is an implicit load control method. In the RIKS method, the load is applied proportionally in several load steps. In each load step, the equilibrium iteration is performed and the equilibrium path is tracked in the load-displacement space. This method is often used in static analysis and shows to be a strong method for nonlinear analysis.

\section{Validation of the proposed FE model}

\subsection{Comparison of moment-rotation curves}

Figure 6 shows the schematic of how the joint rotation ' $\theta$ ' was calculated based on the predicted vertical deflection ' $\mathrm{u}$ ' at a distance of $\mathrm{L}=850 \mathrm{~mm}$ using the expression [15] given below:

$$
\theta=\tan ^{-1}(u / l)
$$

The validation of the proposed finite element model is examined by comparing its numerical results with those obtained experimentally by Abidelah et al. [13] in terms of moment capacity.

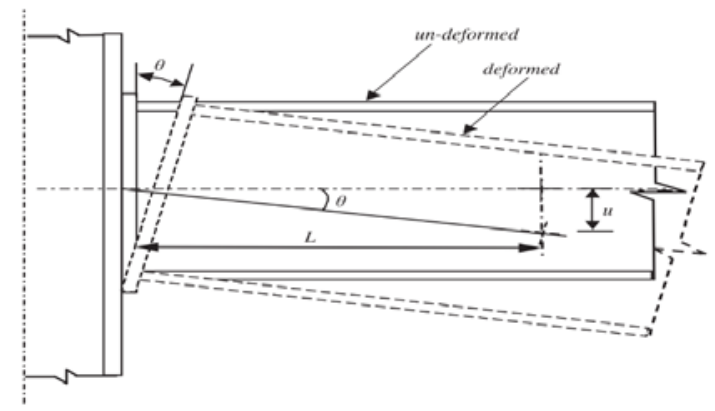

Fig. 6. A sketch of the deflected beam to estimate the connection rotation.

From Table 2 and Fig. 7, it can be seen that finite element model results show good correlation with the experimental results qualitatively and quantitatively and have proven to simulate the behaviour of the connection effectively.

Table 1. Comparison between experimental and FE moment capacity.

\begin{tabular}{|l|c|c|c|}
\hline $\begin{array}{c}\text { Test } \\
\text { configuration }\end{array}$ & $\begin{array}{c}\text { Experimental test } \\
(\mathrm{kN} . \mathrm{m})\end{array}$ & $\begin{array}{c}\text { FE model } \\
(\mathrm{kN} . \mathrm{m})\end{array}$ & $\begin{array}{c}\text { Ratio } \\
\text { FE/EXP }\end{array}$ \\
\hline Test EEP & 54 & 62.06 & 1.19 \\
Test FEP & 48 & 52.03 & 1.08 \\
average & $\mathbf{1 . 1 3}$ \\
\hline
\end{tabular}

\subsection{Comparison of failure modes}

A comparison between the failure mode observed in tests and the one obtained by numerical simulation is shown in Fig. 8. It is clear that, as the displacement increases, an increase of the gap between column flange and end plate in the tensile zone occurs. In compressive zone, the beam flange is subjected to a local buckling. Moreover, the shear deformation of the panel zone was evident. As shown in Fig. 8, the plastic deformation, gap between endplate and column flange, panel zone deformation and local buckling were well simulated. It is clear from the above comparisons that the FE model simulates, with acceptable accuracy, the behaviour of steel endplate bolted connections.

\section{Parametric study}

Based on the verified model, 3D solid models of steel beam-to-column connection (model description shown in Fig. 2) were constructed to investigate the behaviour of two connection types; extended and flush end plate connections. The studied parameters are as follows: end-plate thickness, bolts type and presence of column stiffeners.

The naming convention used for sample identification (XX-BT-S) is a combination of the connection configuration (XX), bolt type (BT) and the presence of column stiffeners (S).

The connection configurations are designated as follows:

- (FEOS) flush stiffened end plate with ordinary bolts.

- (FEP) flush end plate with pretension bolts.

- (EEOS) extended stiffened end plate with ordinary bolts.

- (EEP) extended end plate with pretension bolts.

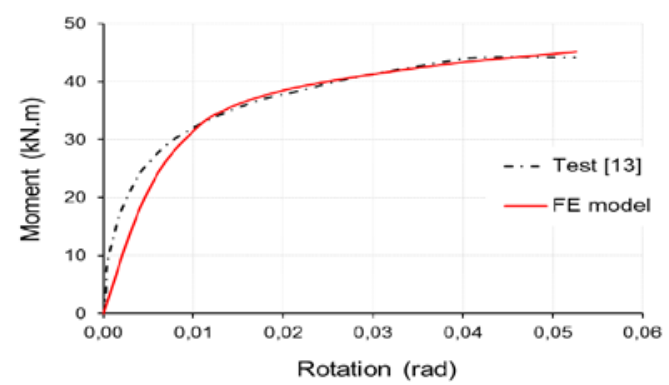

a) Flush end plate (FEP).

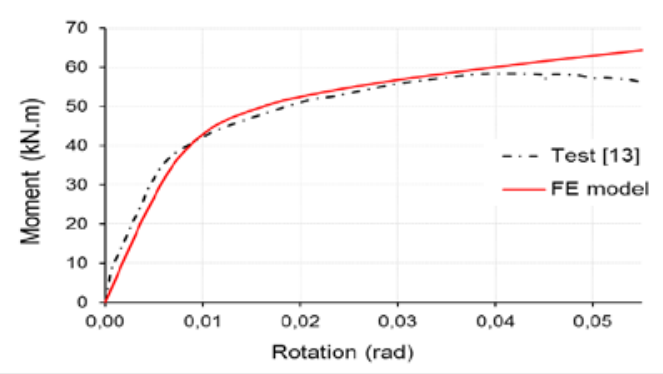

b) Extended end plate (EEP).

Fig. 7. Comparison of moment-rotation curves for two end-plate joints specimens. 

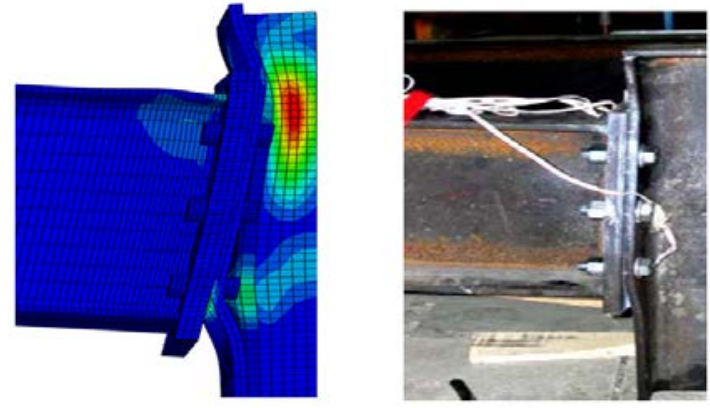

Fig. 8. Experimental and predicted failure modes of the FEP 15.

\section{Results and discussions}

\subsection{Effect of end-plate thickness}

Three end-plate thicknesses $8 \mathrm{~mm}, 15$ and $20 \mathrm{~mm}$ for both connections have been used. The result comparison of the extended end plate is shown in Fig. 9. It can be seen that when the endplate thickness decreases to $8 \mathrm{~mm}$, low moment and rotation capacities are achieved. It is also shown from Fig. 9 and Fig. 10 that the thickness of the endplate has a great influence on the initial rotation stiffness of the bolted extended end plate connections compared to the flush end plate connections.

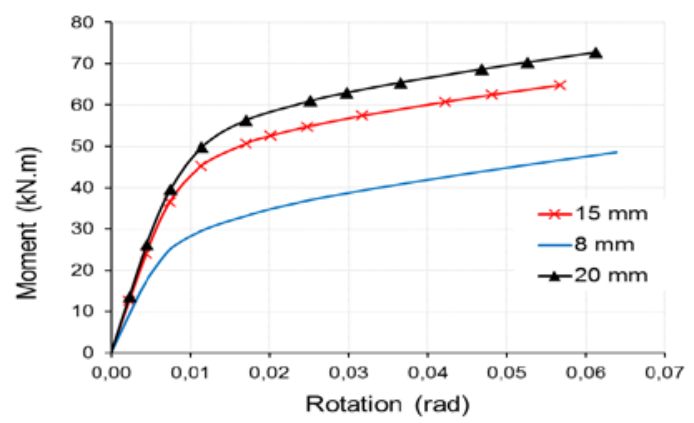

Fig. 9. Moment-rotation curve variation for EEP, with different end plate thickness $\left(t_{p}\right)$.

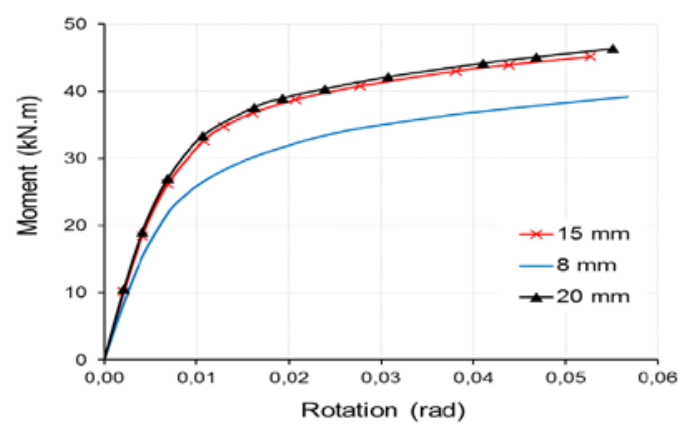

Fig. 10. Variation moment-rotation curve of FEP with different end plate thickness $\left(t_{p}\right)$.

As the thickness increases from 8 to $15 \mathrm{~mm}$, the initial stiffness increases, but when the thickness is greater than $15 \mathrm{~mm}$, little difference is observed between the moment-rotation curve of EEP15 and EEP20. The reason for this is that as the thickness of the endplate increases to a certain value, the strength of the bolt becomes the influential factor, most areas of the endplate remain elastic and the bolt will yield first. This permits higher tensile forces in the bolts which will increase the bending moment. However, the brittle bolt failure was observed when the endplate increased to 15 and $20 \mathrm{~mm}$, which caused the low rotation capacity as the brittle failure of the bolt decreased the rotation capacity of the connection. As the thickness of the plate increased, the mode of failure changed from complete yielding of the flange (end plate 8) to bolt fracture with flange yielding (end plate 15) and to bolt fracture (end plate 20). EC3part1.8 [1] has named these 3 modes of failure of bolted endplate connection as mode 1 , mode 2 and mode 3 respectively.

From the above discussion, it is suggested that for the endplate connections in bending, it is necessary to limit the thickness of the endplate in order to avoid brittle failure of the bolts and to obtain ductile joints by the yielding of the endplate in bending. The endplate should also have a certain thickness to avoid the brittle failure of the endplate itself.

\subsection{Effect of the presence of column stiffeners with ordinary bolts}

The influence of the presence of column stiffeners with ordinary bolts on the behaviour of the end plate connections is studied in this section. Four models are analysed, as shown in Fig. 12. It can be observed that using column stiffeners with ordinary bolts instead of pre-tensioned bolts increases considerably the ultimate moment and the rotation capacity of the connections. In addition, it can be noticed that stiffening the column web increases slightly the initial stiffness of the connection, since the flange column without stiffeners bends easily as shown in the Fig. 13.

The presence of column stiffeners minimizes the deformation in the panel zone of the connection and it has a significant effect on the ultimate moment and rotation capacities than that of unstiffened pre-tensioned bolted connections.

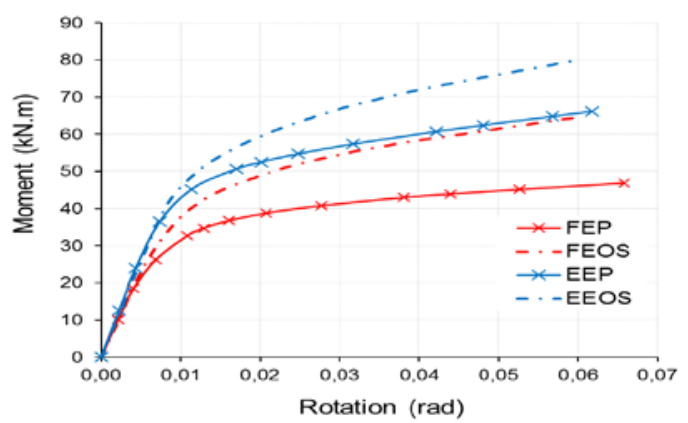

Fig. 12. Moment-rotation curves of the pretensioned bolted and column stiffness joints $\left(t_{p}=15 \mathrm{~mm}\right)$.

Furthermore, the design of end plate connections without column stiffeners will produce column web buckling, leading to a premature failure in the joint. Figure 13 shows that an increase in capacities is rather significant in stiffened connections with ordinary bolts than with pre-tensioned ones. 


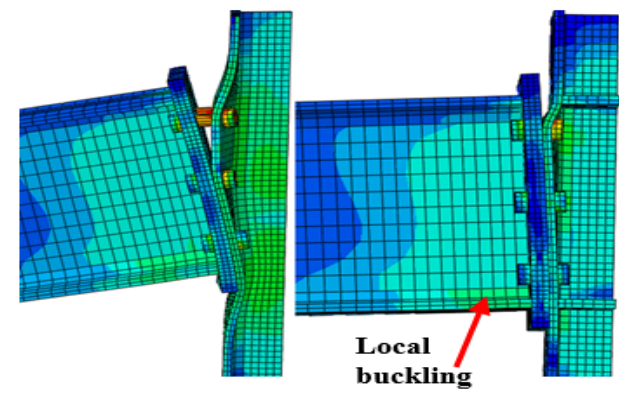

a) Flush end plate connections.
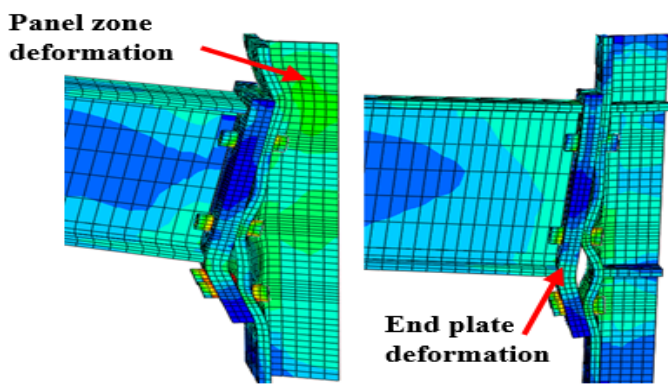

b) Extended end plate connection.

Fig. 13. Distribution of Von Mises stress in EEP and EEOS connections.

\section{Conclusion}

The results presented herein focused on the behavioural variations of bolted extended and flush end plate connections due to changes in plate thickness, bolts type and presence of column stiffeners. Based on the studied results, the following conclusions can be drawn:

- The presence of column stiffeners with ordinary bolts instead of the pre-tensioned bolts alone, gives an important moment capacity but a slight increase on the initial stiffness. For the flush end plate, the effect is more significant.

- The thickness of the end plate has a great influence on the behaviour of extended plate joints compared to the flush ones.

- The comparison between the use of ordinary bolts with column stiffeners and pre-tensioned bolts alone, cannot be achieved, because the economic parameter must be taken into account (design cost, cost of reparation and erection of each type).

Finally, the finite element results, which have been well validated against test results, can provide extra valuable results for the mechanical behaviour of joints, which are difficult to measure in physical tests, such as pressure distribution caused by bolt pretension, friction between the end-plate and the column flange and the principal stress in the connection.

The finite element method allows for further parametric analyses of bolt end-plate connections to be implemented so as to obtain comprehensive results that can be used to propose a complete analytical design procedure that is consistent with the component method of joint design used in Eurocode 3.

\section{References}

1. CEN. Eurocode 3, Design of steel structures. part 1.8: Design of joints, (2005).

2. C. H. Shi G, Shi YJ, Wang YQ, Li S, Experimental study on semirigid end-plate connections in multistory steel frames, J. Tsinghua University (Science Technol., no. 44, p. 391-4, (2004).

3. J. Pertold, R. Y. Xiao, and F. Wald, Embedded steel column bases: I. experiments and numerical simulation," J. Constr. Steel Res., vol. 56, pp. 253270, (2000).

4. L. R. O. De Lima, S. A. L. De Andrade, P. C. G. Da, and L. S. Da Silva, Experimental and mechanical model for predicting the behaviour of minor axis beam-to-column semi-rigid joints, Int. J. Mech. Sci., vol. 44, no. 6, pp. 1047-1065, (2002).

5. G. Shi, Y. Shi, Y. Wang, and M. A. Bradford, Numerical simulation of steel pretensioned bolted end-plate connections of different types and details, vol. 30, pp. 2677-2686, (2008).

6. M. Wang, Y. Shi, Y. Wang, and G. Shi, Numerical study on seismic behaviors of steel frame end-plate connections, JCSR, vol. 90, pp. 140-152, (2013).

7. S. K. Bose, G. M. McNeice, and A. N. Sherbourne, Column webs in steel beam-to-column connexions part II-Design recommendations, Comput. Struct., vol. 2, no. 1-2, pp. 281-301, (1972).

8. Y. I. Maggi, R. M. Gonçalves, R. T. Leon, and L. F. L. Ribeiro, Parametric analysis of steel bolted end plate connections using finite element modeling,vol. 61, pp. 689-708, (2005).

9. C. Díaz, M. Victoria, P. Martí, and O. M. Querin, FE model of beam-to-column extended end-plate joints, J. Constr. steel Res., vol. 67, no. 10, pp. 1578-1590, (2011).

10. H. Thai and B. Uy, Finite element modelling of blind bolted composite joints, JCSR, vol. 112, pp. 339-353, (2015).

11. H. Augusto, C. Rebelo, and L. S. Silva, Modelling of the Dissipative Behaviour of Partial-Strength Beamto-Column Steel Connections, 15th World Conf. Earthq. Eng., no. 1994, (2012).

12. E. R. Romero, Finite element simulation of a bolted steel joint in, Tampere university of technology Elena, (2010).

13. A. Abidelah, Analyse numérique du comportement d'assemblages métalliques. Approche Numérique Et Validation Expérimentale, Université Blaise Pascal Clermont II, 2009.

14. B. Gil and E. Bayo, An alternative design for internal and external semi-rigid composite joints. Part II : Finite element modelling and analytical study, Eng. Struct., vol. 30, pp. 232-246, (2008).

15. K. S. Al-Jabri, A. Seibi, and A. Karrech, Modelling of unstiffened flush end-plate bolted connections in fire, J. Constr. Steel Res., vol. 62, no. 1-2, pp. 151-159, (2006).

16. ABAQUS user'smanual version 12.1. Pawtucket, R.I.: Hibbit. Karlsson and Sorenson, (2012). 